\title{
Functional food: complementary to fight against COVID-19
}

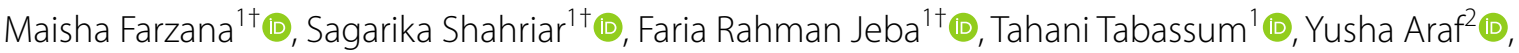 \\ Md. Asad Ullah³ ${ }^{3}$ Jarin Tasnim ${ }^{4}$, Agnila Chakraborty ${ }^{4}$, Taslima Anjum Naima ${ }^{4}$, Kay Kay Shain Marma ${ }^{4}$, \\ Tanjim Ishraq Rahaman ${ }^{5}$ and Mohammad Jakir Hosen ${ }^{2^{*}}$ (1)
}

\begin{abstract}
Background: The novel coronavirus has embarked on a global pandemic and severe mortality with limited access for its treatments and medications. For the lack of time, research, and enough efficacy, most vaccines are underdeveloped or unreachable to society. However, many recent studies suggest various alternative, complementary remedies for COVID-19, which are functional foods. This review provides an overview of how functional foods can play a great role through modulating the host immune system, generating antiviral activities, and synthesizing biologically active agents effective against the coronavirus.
\end{abstract}

Main body: This review article summarizes the natural defense mechanisms in tackling SARS-CoV-2 alongside conventional therapeutic options and their corresponding harmful side effects. By analyzing bioactive components of functional foods, we have outlined its different contributions to human health and its potential immunomodulatory and antiviral properties that can enhance resistivity to viral infection. Moreover, we have provided a myriad of accessible and cost-effective functional foods that could be further investigated to target specific key symptoms of COVID19 infections. Finally, we have found various functional foods with potent bioactive compounds that can inhibit or prevent COVID-19 infections and disease progression.

Short conclusion: Numerous functional foods can help the body fight COVID-19 through several mechanisms such as the reduced release of pro-inflammatory cytokines, reduced expression of ACE2 receptors in cells, and inhibiting essential enzymes in SARS-CoV-2.

Keywords: Functional food, Immune system, Vitamins, Medicinal plants, Probiotics

\section{Background}

The pandemic "Coronavirus Disease 2019" (COVID-19) is caused by Severe Acute Respiratory Syndrome Coronavirus 2 (SARS-CoV-2) and was officially identified in late December 2019 at Wuhan, China. COVID-19 is highly contagious and mainly characterized by mild to severe

\footnotetext{
*Correspondence: jakir-gen@sust.edu

†Maisha Farzana, Sagarika Shahriar and Faria Rahman Jeba have contributed equally to this article

2 Department of Genetic Engineering and Biotechnology, School of Life Sciences, Shahjalal University of Science and Technology, Sylhet, Bangladesh

Full list of author information is available at the end of the article
}

respiratory infections in humans [1]. SARS-CoV-2 is mainly spread by respiratory droplets of an infected individual while coughing, sneezing, and talking. As of 10th February 2022, more than 404 million cases with over 5.5 million deaths have been reported worldwide [2]. Moreover, many countries of the world have faced several waves of reoccurring pandemic with different mutated strain of this virus [3].

The vaccine is the ultimate target to prevent and control COVID-19. Currently, there are 13 authorized vaccines available against SARS-CoV-2 with an accuracy of $75-95 \%[4,5]$. However, as of February 2022, a total of 10.1 billon vaccine doses have been administered 
[6]. Every country of the world is looking for these vaccines, but due to urgent demand compared to production capacity, high price, less efficacy, and possible side effects, it may take years to ensure vaccination $[7,8]$. As a result, most affected countries implemented complimentary restrictive measures, including wearing masks, social distancing, and lockdowns to slow down the spread of this virus.

Moreover, synthetic antiviral drugs are also underdeveloped, expensive, might have adverse impacts, and are only used in selected situations to reduce the duration of illness [9-11]. Thus, it necessitates alternative, complementary remedies for COVID-19. The rapid changes in the strains of SARS-CoV-2 have led to diversified forms of medications and dietary profiles for controlling and preventing the infection risk [12]. Functional foods can play a great role through modulating the host immune system, generating antiviral activities within the host, and synthesizing biologically active agents effective against the current COVID-19 pandemic [13]. This review featured the possible pathomechanism of SARS-COV-2 and the mechanisms of functional food to fight against it.

\section{Pathomechanism of COVID-19}

The pathogenesis of COVID-19 is still not fully understood. SARS-CoV-2 is primarily transmitted by microdroplets exhaled by infected individuals or fomites and bind with the ACE2 receptor to get entry to lung cells, and then the virus targets type-II $\mathrm{ACE}^{+}$alveolar cells present in the lungs [14]. The infected lung cells secrete cytokine IL-8, which attracts T lymphocytes and neutrophils [15]. The innate immune system initially attempts to defend the body in various ways: mucosa-associated lymphoid tissues (MALT) protect mucosal surfaces, and Pattern Recognition Receptors (PRR) such as TLR7 recognize pathogen-associated molecular patterns (PAMPS). Additionally, activation of transcription factors such as nuclear factor $\mathrm{\kappa B}(\mathrm{NF}-\mathrm{\kappa B})$ and activator protein 1 (AP-1) results in the release of pro-inflammatory cytokines such as IL-6, TNF- $\alpha$, and interferon 1 [1618]. Due to the secretion of various chemokines, innate immune cells accumulate in the area of infection, which releases even more chemokines and recruit lymphocytes leading to antigen presentation via dendritic cells [19-21].

Meanwhile, neutrophils at the infection site attempt to eliminate the virus by using neutrophil extracellular traps (NETs), phagocytosis, and oxidative burst [22]. Antigen presentation starts the phase of adaptive immune response where it depends on $\mathrm{T}$ lymphocytes. Helper $\mathrm{T}$ cells stimulate B cells to produce SARS-Cov-2-specific antibodies, while Cytotoxic $\mathrm{T}$ cells remove infected cells. Research has shown that $80 \%$ of cell infiltration is done by Cytotoxic T cells in COVID-19 patients [23]. If Cytotoxic $\mathrm{T}$ cells fail to eliminate infected cells and the disease progress for a longer time, the release of pro-inflammatory cytokines becomes uncontrollable, leading to a cytokine storm. Ultimately, multiple complications such as acute respiratory distress syndrome (ARDS) and organ failure [24] occur in infected patients, which can eventually progress to death (Fig. 1). The overall process is summarized in Fig. 1.

\section{Functional food and its essential components and properties}

Functional foods, also known as nutraceuticals, are defined as foods containing bioactive compounds that have beneficial effects on consumer health. Bioactive compounds are phytochemicals extracted and consumed as supplements or may have medicinal value when engulfed as whole food. Functional food has gained popularity to prevent numerous diseases, boost growth, and enhance host metabolic activity [25, 26]. In addition, such functional foods may be useful for preventing noncommunicable diseases like COVID-19.

\subsection{Essential components of functional foods \\ 3.1.1 Multivitamins}

Functional food has several essential components, including vitamins. Vitamins are organic compounds required in the diet for the growth and development of the body. Serving countless functions in the body, deficiency of vitamins can hinder the proper functioning of the body and contribute to improper immune responses to infections. A summary of essential vitamins and their rules in the body found in different functional foods is summarized in Table 1.

\subsubsection{Minerals}

Minerals are inorganic, required in small amounts in the body for various functions, including adequate functioning of the immune system [47]. Some minerals are required in larger amounts, e.g., calcium, phosphorus, magnesium, sodium, potassium, and chloride. Others are required in minute amounts, also known as trace minerals, including zinc $(\mathrm{Zn})$, copper $(\mathrm{Cu})$, selenium $(\mathrm{Se})$, and iron $(\mathrm{Fe})$, serve critical roles in many biochemical processes (Table 2). Similar to vitamins, a deficiency in such elements hampers health [47]. Minerals, both abundant and trace, and their contributions to the immune system are outlined in Table 2.

\subsubsection{Nutraceuticals supplements}

Nutraceuticals, derived from "nutrition" and "pharmaceutics," are substances used to improve health, slow down aging, enhance life expectancy, protect 


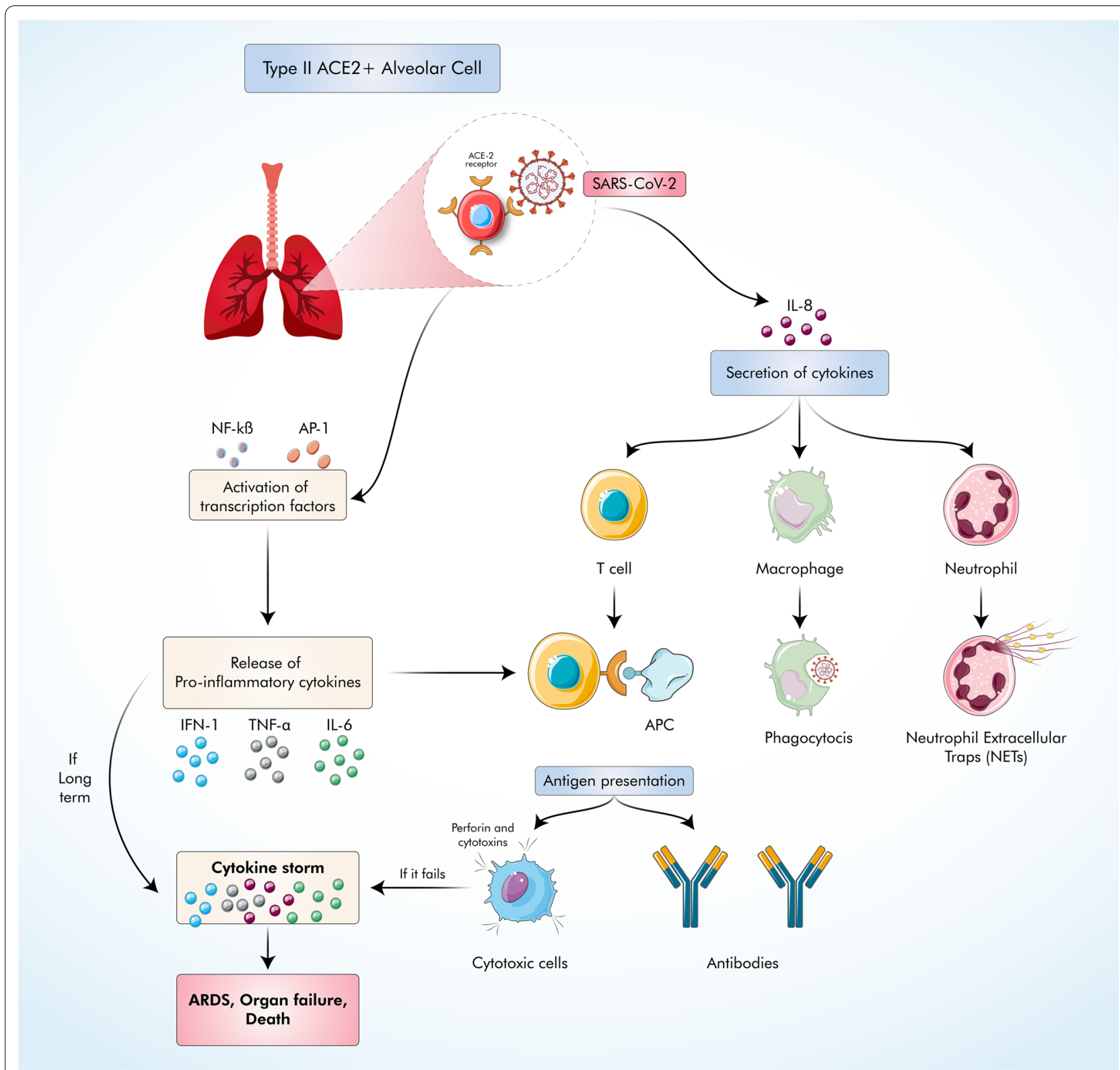

Fig. 1 SARS-CoV-2 infects primarily alveolar cells through the ACE2 receptor. The immune system responds to the virus by activating different transcription factors that release pro-inflammatory cytokines that trigger the accumulation of immune cells leading to antigen presentation. Additionally, secretion of specific cytokines such as IL-8 attracts neutrophils and macrophages to the site of infection alongside T lymphocytes. While neutrophils kill by oxidative burst and NETs with macrophages inducing phagocytosis, CD4 +T cells help to activate B cells producing anti-SARS-CoV-2 and CD8 + T cells kill infected cells through the release of perforins and cytotoxins. If CD8 + T cells fail to kill the virus in the presence of inflammatory cytokines over the long term, cytokine storm occurs, leading to disease progression and complications such as ARDS, organ failure, and death

from chronic illnesses or help the body functions [51]. Nutraceutical products originate from herbs, diet supplements, particular diets, and processed foods. Research has indicated the successful application of nutraceutical products for treating various disorders such as diabetes, atherosclerosis, CVDs, cancer, and neurological disorders (Table 3) [51]. While a myriad of nutraceutical supplements is available on the market, specific nutraceutical supplements are provided in Table 3 to summarize the overall benefits of nutraceuticals. 


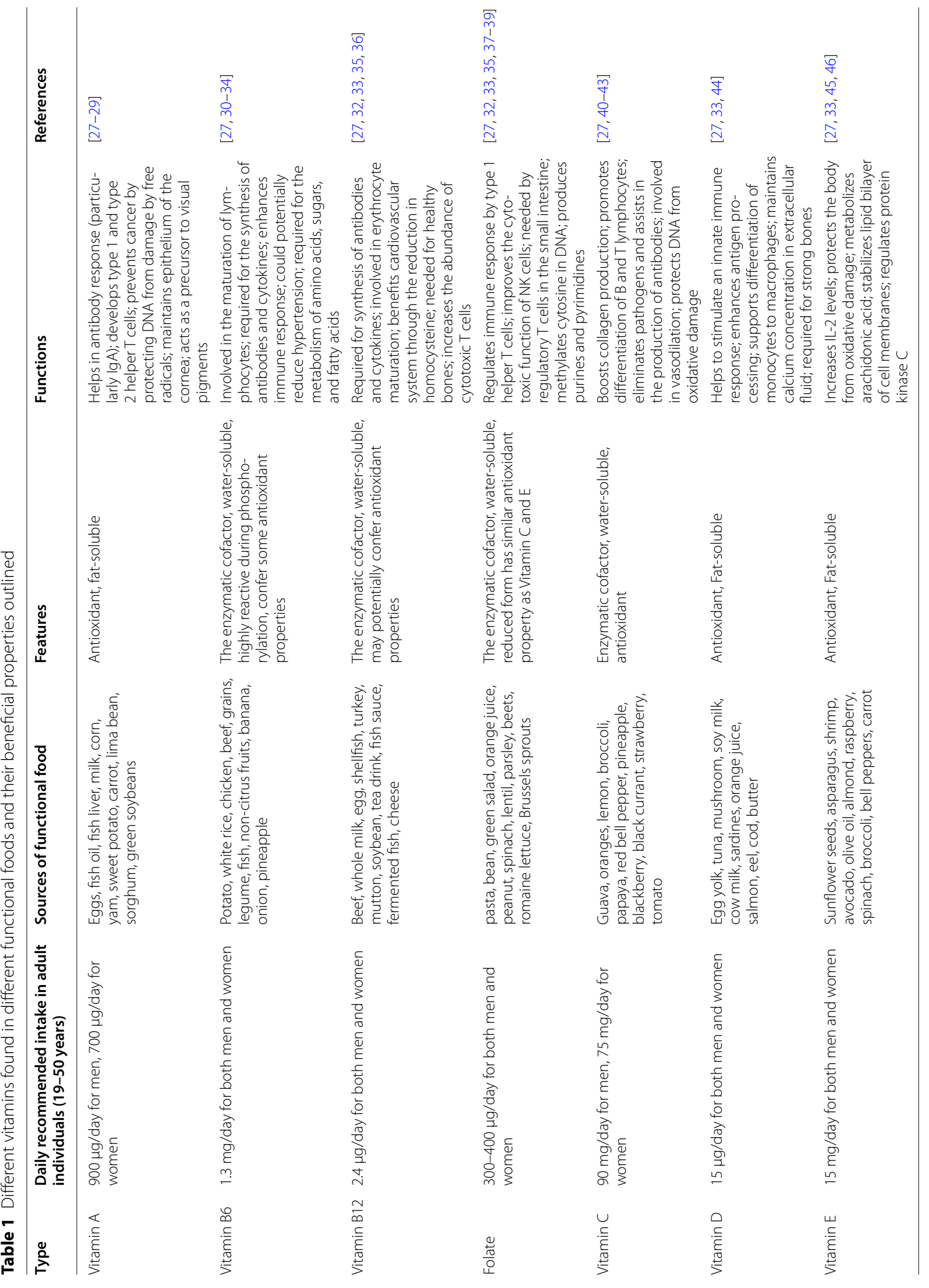




\subsubsection{Probiotic supplements}

Probiotics are live microorganisms that provide benefits to the host when ingested in adequate amounts [55]. Strains belonging to Lactobacillus and Bifidobacterium sp. are commonly used as probiotic preparations in fermented milk and yogurt. Probiotics maintain a healthy balance between pathogenic and non-pathogenic bacteria alongside pro-inflammatory and anti-inflammatory cytokines [51]. Furthermore, probiotics improving gut microbiome affect viral vaccine responses [56]. Therefore, probiotics might play a significant role in fighting COVID-19 by mediating the immune response of the infected patients.

\subsection{Properties of functional food 3.2.1 Immunomodulatory Properties}

Functional foods play immunomodulatory roles by improving both adaptive and innate immune responses, which are imperative to the viability of living organisms [26]. Additionally, functional foods facilitate the release of immunostimulatory chemicals like cytokines and stimulate TNF- $\alpha$ and macrophage release that strengthen the body's defense [57, 58]. Various explanations have been proposed for these effects, including the interaction of immunomodulatory peptides and opioid receptors on the immune cell surface, presence of arginine at $\mathrm{C}$-terminal of peptides similar to ACE-inhibitory peptides, and activation of reactive oxygen species [58]. Consequently, deficiencies in diet had negative consequences on immune system functions suggesting immunomodulatory functions of these nutrients. For example, protein-energy malnutrition (PEM) had reduced lymphocyte proliferation and opsonic plasma activity [59]. In other instances, reduced zinc levels resulted in lower cytokine concentration in plasma alongside less proliferation of $\mathrm{T}$ cells, while a vitamin B6 deficiency led to a decrease in antibody-forming cells $[60,61]$.

\subsubsection{Antiviral activities}

The antiviral properties of functional foods have also been documented to be effective against different viruses. Glycyrrhizin is effective against Japanese encephalitis virus, Human immunodeficiency virus type 1 (HIV-1), and chronic hepatitis $\mathrm{C}$ virus (HCV) [62]. Glycyrrhizin in licorice roots has been shown to inhibit SARS-CoV replication as it affects cellular signaling pathways and induces nitrous oxide synthesis in macrophages, preventing the virus from replicating [12]. Epigallocatechin gallate (EGCG), found in green tea and its ester derivatives, has proven to inhibit the NS3/4A protease enzyme responsible for activating functional proteins in $\mathrm{HCV}$ [63].
Moreover, EGCG derivatives inhibit an $\alpha$-glucosidase enzyme that prevents glycoprotein synthesis for the viral envelope [63]. Sulfated polysaccharides in seaweed compete with viruses for the binding site on cells and prevent their entry by synergistic interaction with the cell [64]. Therefore, consumption of seaweed is shown to be effective against Herpes simplex virus Types 1 and 2 (HSV-1 and HSV-2), human cytomegalovirus (HCMV), HIV-1, respiratory syncytial virus (RSV), influenza virus, and bovine viral diarrhea virus [64].

\subsubsection{Additional features}

In addition to immunomodulatory and antiviral properties, functional foods also have antibacterial, antifungal, antioxidant, anticancer, anti-inflammatory, and neuroprotective properties [65-75].

\section{Currently available non-specific treatment options for COVID-19 and their side effects}

Several domestic and foreign companies are using various technologies to develop antiviral drugs, immunotherapies, and vaccines with a diverse ranging limit of accuracy. Patients with early infection are mostly given antiviral agents to reduce viral load. However, patients with severe and late infections are given anti-inflammatory drugs [76]. These antibacterial and anti-inflammatory drugs are administered to prevent and treat probable secondary bacterial infections only. Hence, these cannot assure any direct or promised recovery from the virus itself. Besides, these drugs, potential vaccines, and therapies are still underdeveloped, raising the concern of creating various minor to severe side effects (Table 4). Moreover, the availability of these treatments is not yet reachable to many people depending on their geographical and economical differences. A selection of drugs and treatments being tested for COVID-19 is presented in Table 4.

\section{Role of functional foods on respiratory and viral diseases}

Respiratory viruses are the most frequent causes of human illness, which can cause respiratory tract infections that can range from mild to lethal [102]. To prevent respiratory tract infections, medicinal plants had been used for centuries in almost all cultures worldwide as traditional medicines. Leaves, roots, stems, fruits, flowers, and several other natural substances extracted from plants with therapeutic potential had been used to make herbal medicines. In addition, probiotics can have served as functional food supplements, which had the potential to cure several such health problems $[103,104]$. 


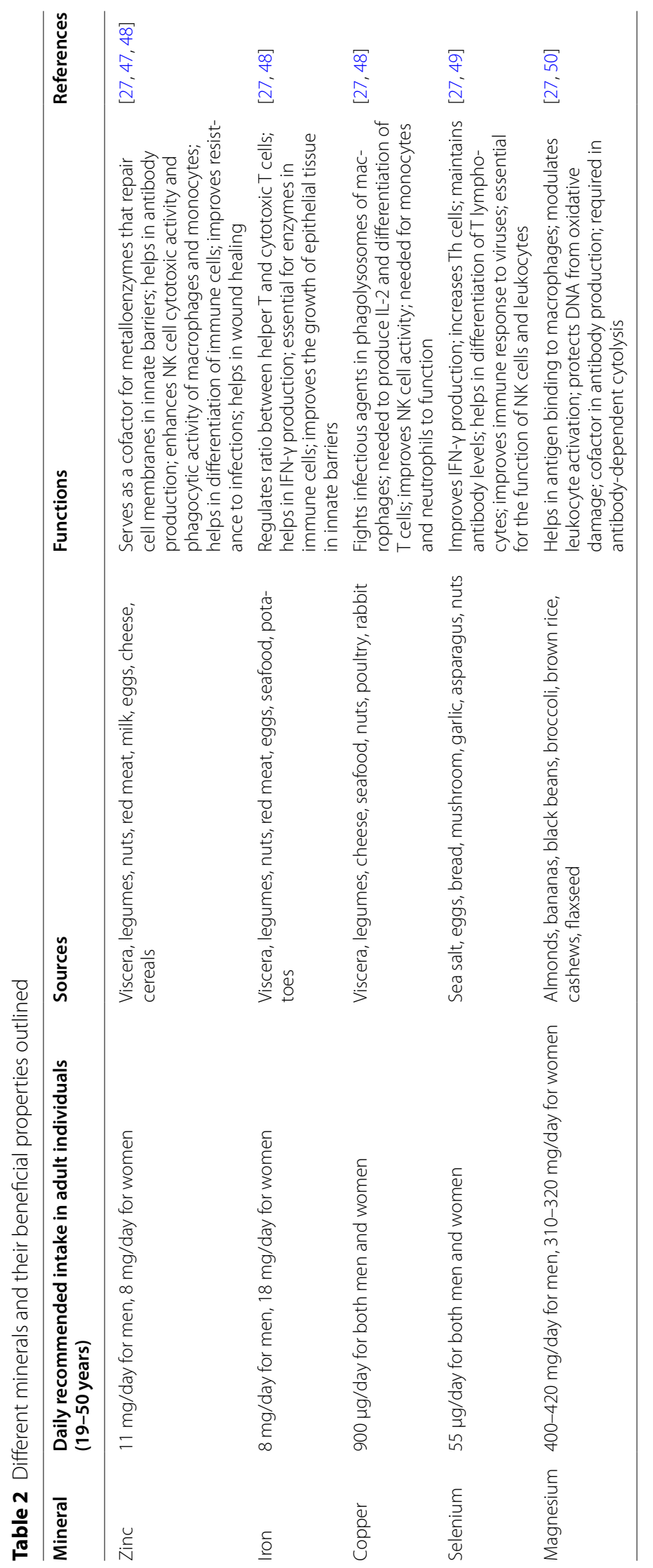


Table 3 Selected nutraceutical supplements with their associated benefits summarized

\begin{tabular}{|c|c|c|c|}
\hline Nutraceutical supplement & Source (s) rich in the nutraceutical compound & Functions & References \\
\hline Quercetin & Onion, red grapes, broccoli, citrus fruits & $\begin{array}{l}\text { Protects blood vessels from oxidative stress and low- } \\
\text { density lipoprotein }\end{array}$ & {$[51,52]$} \\
\hline Omega-3 fatty acids & Fish & $\begin{array}{l}\text { Treats eye disorders such as age-related macular } \\
\text { degeneration (AMD); prevents heart damage in diabetic } \\
\text { patients }\end{array}$ & [51] \\
\hline Cod liver oil & Cod liver & Reduces symptoms of cardiovascular-related conditions & {$[51,53]$} \\
\hline Ginseng & Panax ginseng, Panax quinquefolius & $\begin{array}{l}\text { Protects against infections; delays osteoporosis; pre- } \\
\text { vents and treats autoimmune diseases }\end{array}$ & [54] \\
\hline Lutein & Kale, spinach, corn, eggs & $\begin{array}{l}\text { Combats oxidative stress; delays Alzheimer's disease; } \\
\text { treats visual disorders such as AMD }\end{array}$ & {$[51,52]$} \\
\hline
\end{tabular}

Like other members of the coronavirus family, SARS$\mathrm{CoV}-2$ causes severe respiratory tract infections and chronic obstructive pulmonary diseases (COPDs). Previous studies have shown that dietary supplement solutions containing whey protein, carbohydrates, and antioxidants helped increase the human body's muscle strength by improving airflow limitation and reduced blood levels of inflammatory cytokines $[105,106]$. In addition, it also showed that intake of vitamin $\mathrm{E}$ and $\mathrm{D}$ decreased the level of COPD risk, mortality rate, and increased inspiratory muscle strength $[107,108]$.

Several vitamins, including Vitamin C and E, have been reported to play a significant role in alleviating the immune response against respiratory viral agents [109, 110]. Respiratory infections deliberately lower the vitamin count from cells, negatively affecting the immune system causing severe diseases. Functional foods containing these vitamins have shown potential antioxidant effects against pulmonary diseases and prevented the severity of the infections [111, 112]. Moreover, fruits and vegetables containing $\beta$-Carotene and Lycopene have also shown free radical-scavenging activity and antioxidant effect against COPDs [113, 114]. Dietary supplements, vegetables, and fruits can also work over secondary bacterial infections due to coronavirus diseases, as they are important sources of nutrients, dietary fiber, and phytochemicals. A respiratory allergy experimental model has shown that probiotics induce a clear Th1 (elaborate) balance within the infected host favoring the production of IgG instead of IgE immunoglobulin and increasing the levels of IL-10 and IFN- $\gamma$ cytokines, which reduces infection severity [115].

Medicinal plants were also used as supplements to treat SARS, MERS, and influenza viruses. Plant-based phenolic compounds from medicinal plants such as Dioscorea batatas, Glycyrrhiza radix, Mollugo cerviana, Polygonum multiflorum Thunb., Psoralea corylifolia, Rheum officinale Baill., Salvia miltiorrhiza, and Trichosanthes cucumerina L. were shown active against coronaviruses [116, 117]. Moreover, Houttuynia cordata has been found safe and effective for treating pneumonia caused by SARS-CoV and MERS-CoV [118]. A traditional Chinese medicine, Lianhuaqingwen, has been widely used to treat fever, cough, fatigue, influenza, bronchitis, pneumonia, early-stage measles [119, 120].

Another study revealed that Q. Infectoria, B. integerrima, C. microphylla, and O. acanthium extracts could exhibit ACE inhibition and antioxidant activities, which can be consumed as supplements [121]. These species could be promising sources of antiviral molecules that can decrease the reactive oxygen species (ROS) production in infected cells and target different oxidative stressrelated signaling pathways resulting in a reduction in viral spread [122].

Therefore, functional food, dietary and herbal-based supplements have shown a huge impact in combating the symptoms of coronaviruses and increasing the potential activity of human immunity [123]. Furthermore, besides promising inhibitory effects, these food supplements are safe and efficient according to their consumption limit.

\section{Potential roles of functional foods for alleviating COVID-19}

A combination of few common foods is sufficient to prevent many diseases and even alleviate symptoms of patients. For example, herbs such as garlic could be easily added to daily meals, improving the utility of such dishes alongside palatability. For example, bioactive compounds in garlic can inhibit the main protease in SARS-CoV-2, reducing the spread of the virus inside the patient's body (Table 5). Also, the simple and easy addition of beverages such as green tea can be immensely helpful in the prevention of critical life-threatening diseases. Therefore, supplementing expensive drugs and therapy with costeffective, simple food ingredients may be the best option for many patients, particularly those who cannot afford conventional medical treatments (Fig. 2). 
Table 4 Possible non-specific treatments for the management of COVID-19

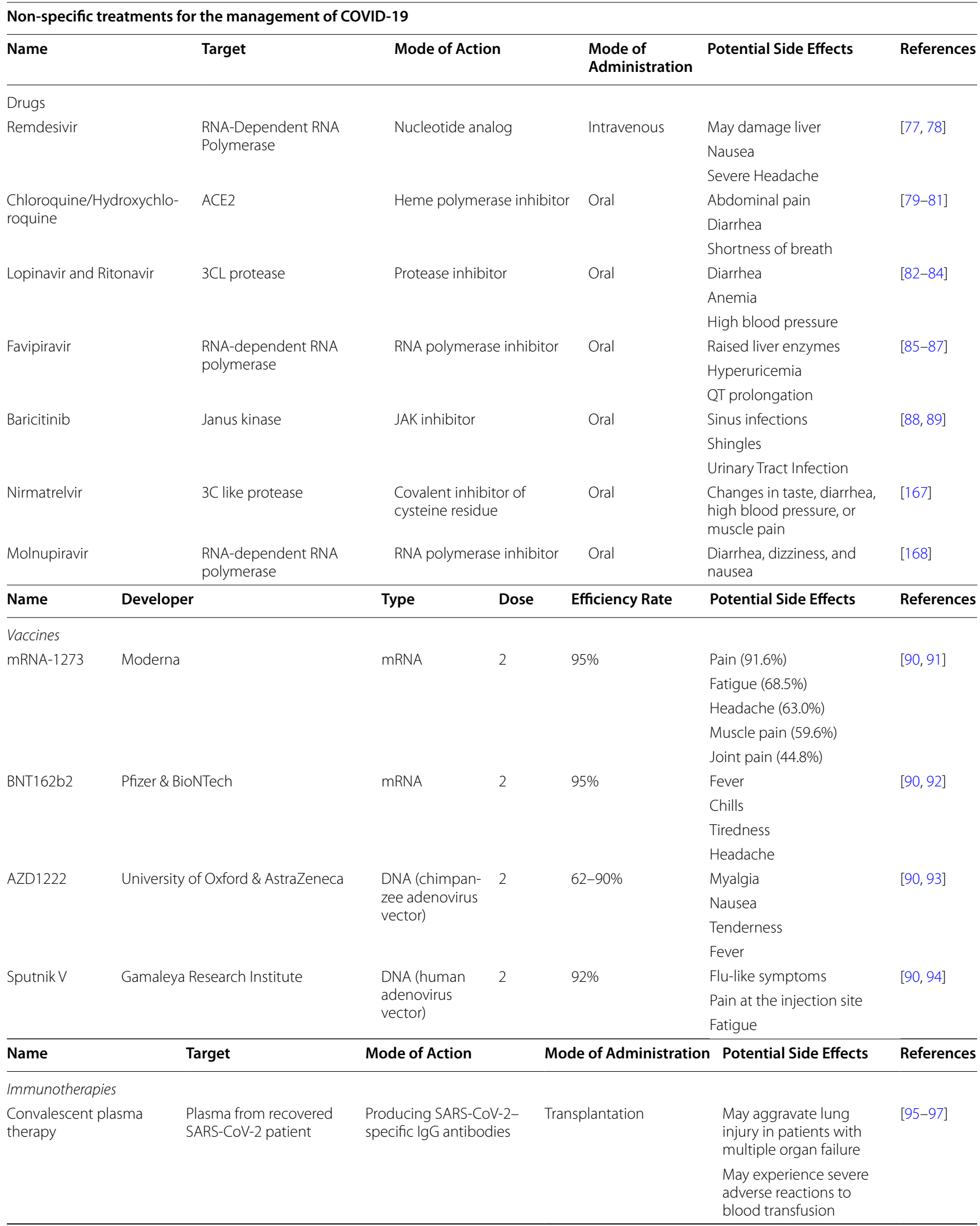


Table 4 (continued)

\begin{tabular}{|c|c|c|c|c|c|}
\hline Name & Target & Mode of Action & Mode of Administration & Potential Side Effects & References \\
\hline \multirow[t]{3}{*}{ Plasmapheresis } & \multirow{3}{*}{$\begin{array}{l}\text { Blood component } \\
\text { separator }\end{array}$} & \multirow{3}{*}{$\begin{array}{l}\text { Discarding pathogenic } \\
\text { substances from patient's } \\
\text { plasma }\end{array}$} & \multirow[t]{3}{*}{ Transplantation } & Hypotension & \multirow[t]{3}{*}[95,98,99]{} \\
\hline & & & & $\begin{array}{l}\text { Risk of transfusion reac- } \\
\text { tions }\end{array}$ & \\
\hline & & & & $\begin{array}{l}\text { Suppression of the } \\
\text { immune system }\end{array}$ & \\
\hline \multirow{2}{*}{$\begin{array}{l}\text { Mesenchymal stem cell } \\
\text { therapy }\end{array}$} & \multirow{2}{*}{$\begin{array}{l}\text { Inhibit excessive immune } \\
\text { responses }\end{array}$} & \multirow{2}{*}{$\begin{array}{l}\text { Preventing uncontrolled } \\
\text { mass production of } \\
\text { cytokines or inflamma- } \\
\text { tory factors }\end{array}$} & \multirow[t]{2}{*}{ Transplantation } & Tumorigenesis & \multirow{2}{*}{$\begin{array}{l}{[95,100} \\
101]\end{array}$} \\
\hline & & & & $\begin{array}{l}\text { Genetic instability and } \\
\text { chromosomal }\end{array}$ & \\
\hline
\end{tabular}

Furthermore, intake of these simple foods is a good endeavor for avoiding many illnesses in the first place. While specific phytochemicals in these foods have the potential to mitigate COVID-19 (Fig. 3), large-scale clinical trials are required to propagate and justify the utilization of such foodstuffs for COVID-19 patients. A list of various functional foods is given in Table 5 .

The severity of COVID-19 infections in patients consists of several key elements targeted with functional food as a therapeutic option instead of relying on costly medicines. One of the main symptoms of COVID-19 is a dry cough that is a nuisance to the patient and can propagate the virus particles into the air and other spaces, increasing the chance of infection. In some patients, coughing turns more severe and causes shortness of breath. Anti-inflammatory foods such as ginger can help reduce coughing. In addition, different compounds such as 6-gingerol and 8-gingerol relax the smooth muscles in the upper airways, reducing the incidence of coughing [146].

Additionally, Treg cells responsible for preventing cytokine storm alongside its associated complications are reported to be reduced in COVID-19 patients [147, 148]. COVID-19 patients have reported thrombotic complications associated with vitamin D deficiency. Therefore, consuming vitamin D-rich foods such as mushrooms, milk, and egg yolk can help prevent such complications. Minerals such as zinc also decrease COVID-19 infections that reduce autophagy and allow in vitro RdRp activity in SARS-CoV-2 [149]. Zinc-rich foods such as eggs modulate the function and abundance of immune cells alongside cytokine production, stimulate autophagy, improve antiviral drugs' efficacy, and inhibit the processing of viral polyproteins.

Secondary bacterial infections contracted from longterm clinical settings have been an important recurrence in hospitalized COVID-19 patients. Healthcare-associated infections coupled with less strict antibiotic stewardship approaches led to antibiotic-resistant pathogens in the ICU and other areas of the hospitals. Overall, Gram-negative bacteria were more prevalent in patients with the infectious agent varying according to the length of the hospital stay $[150,151]$. In one hospital, Klebsiella pneumoniae was the predominant pathogen [151]. Garlic oil has demonstrated antimicrobial effects against Klebsiella pneumoniae and other pathogens [152]. Probiotics such as Pediococcus pentosaceus Li05 can be an effective prophylaxis to treat gastrointestinal infections [153].

Furthermore, SARS-CoV-2 alters redox homeostasis, accumulates excess reactive oxygen species (ROS), and produces oxidative stress in the body leading to lung and endothelial damage, cytokine storm, and insulin resistance [154]. Broccoli seeds were tested on COVID-19 patients, which quickly reduced cough, gastrointestinal symptoms, and other conditions associated with cytokine storm [155]. Nutrients interacting with nuclear factor (erythroid-derived 2)-like 2 (Nrf2), the most potent antioxidant, are present in various foods such as cabbage and fermented vegetables, which can downregulate the oxidative stress associated with COVID-19.

Importantly, post-COVID-19 complications can manifest in recovering individuals such as skeletomuscular symptoms (fatigue, muscle pain), gastrointestinal symptoms (diarrhea, nausea, vomiting), and neuronal symptoms (stroke, loss of taste/smell) [156]. Various functional foods can help alleviate these symptoms-Astragalus radix for fatigue; Sumac extract for muscle pain; zinc supplements for diarrhea, ginger for nausea and vomiting; omega-3 fatty acids for stroke, liposomal lactoferrin supplement for loss of taste/smell [157-161]. Finally, replication of SARS-CoV-2 can be prevented by inhibiting the essential protease enzymes, as demonstrated by molecular docking studies of compounds in garlic, ginger, Neem, tulsi, black pepper, and tea. In addition, foods such as licorice can downregulate ACE2 receptors, blocking viruses from entering cells (Table 5).

While many functional foods have been studied, countless foods targeting COVID-19 infections can be 


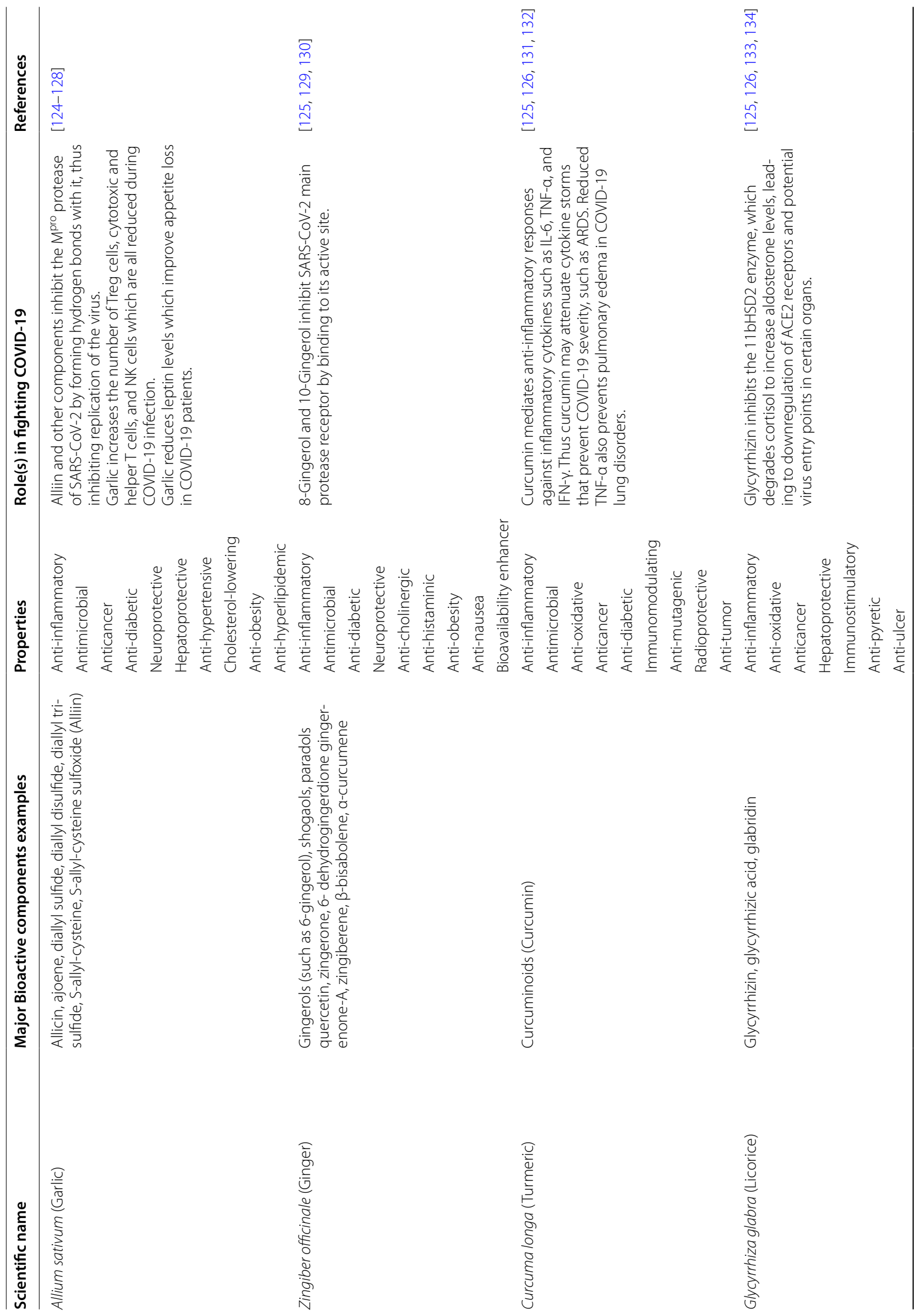




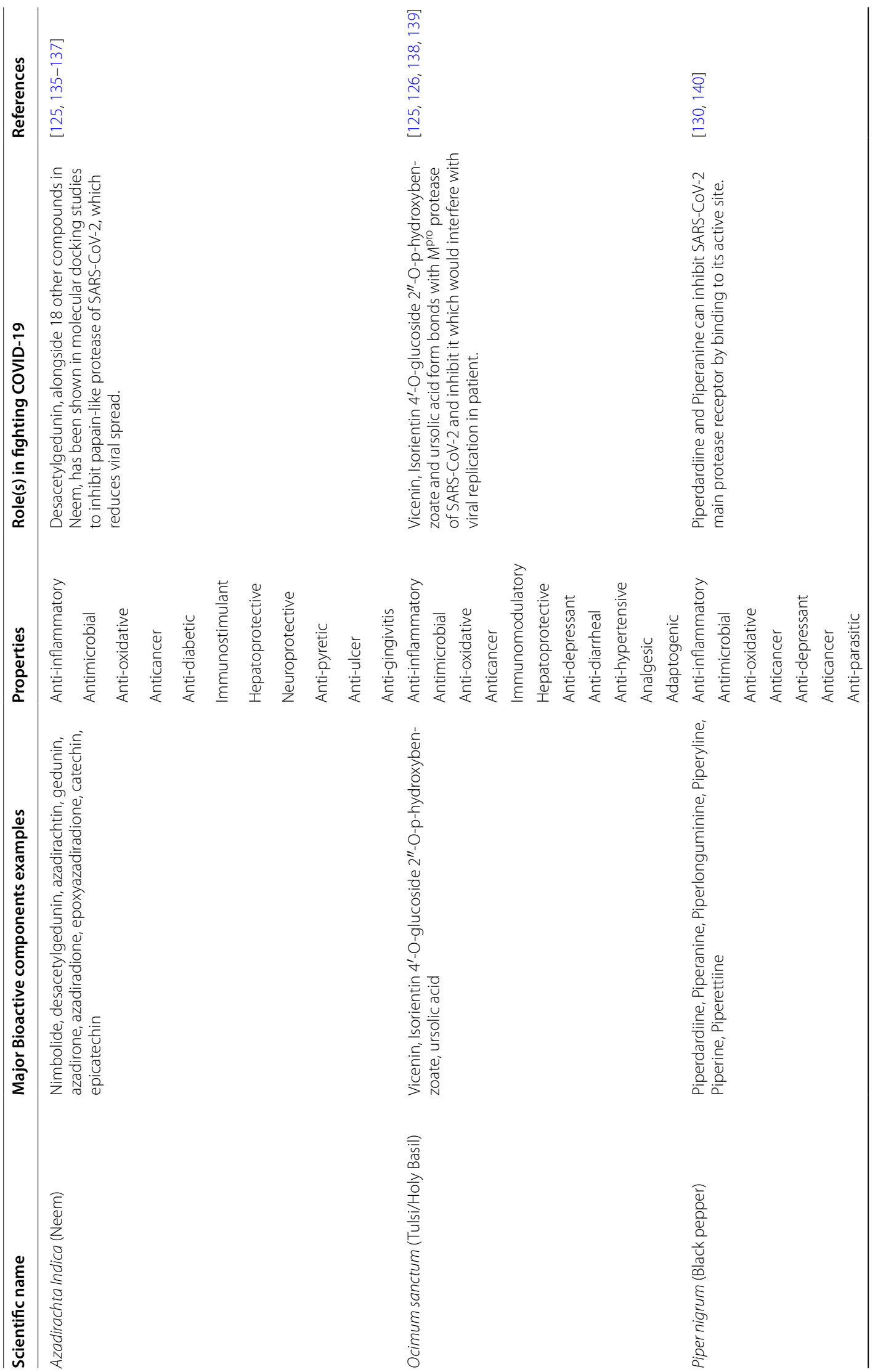




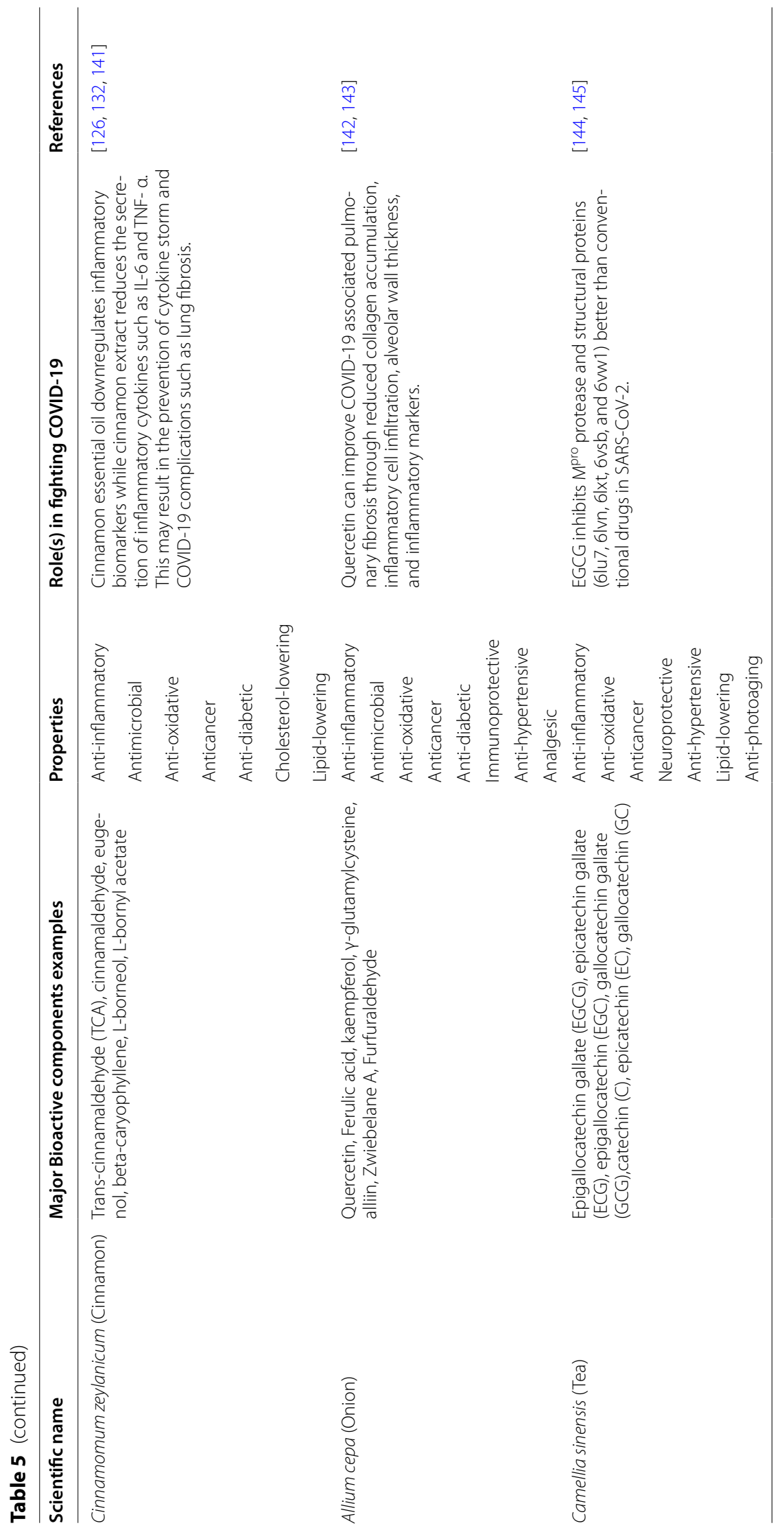


CONVENTIONAL THERAPY

Vaccines
- Side effects such as
blood clots.
- Not 100\% accurate.
- Not available to
everyone yet.
- Long-term effect not
studied.
- Side effects such as
liver damage.
- Non-specific.

\section{FUNCTIONAL FOOD THERAPY}

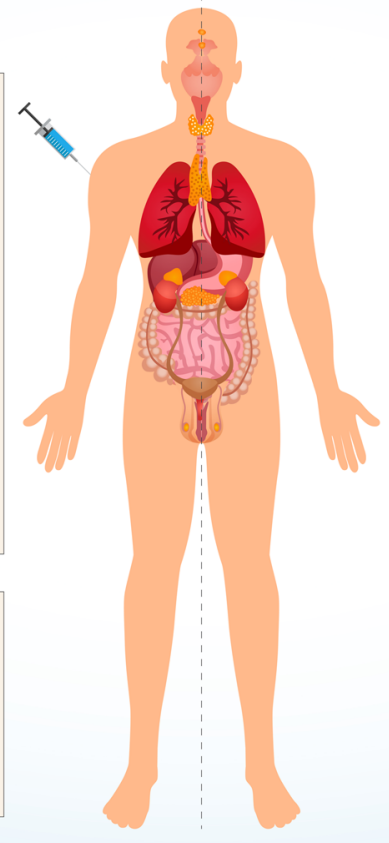

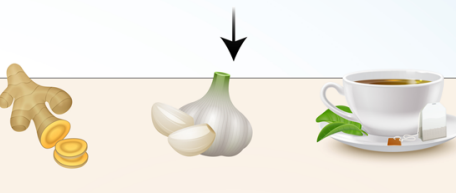

- Safe within daily intake level.

- Easily accessible and cost-effective.

- No particular side-effects.

- Provide additional benefits \& boost health.

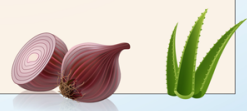

Fig. 2 Comparison of conventional COVID-19 therapies with functional food therapy. Vaccines and drugs, both part of conventional therapy, pose many challenges such as side effects, inaccessibility, non-specificity, and inaccuracy. In addition, the long-term accuracy and side effects of all COVID-19 vaccines have not been studied, making vaccine treatment very uncertain. In contrast, functional foods are simple, cost-effective food ingredients that are available to everyone. Furthermore, since daily intakes for these foods have been studied rigorously and established, they are safe to consume while providing additional benefits and improving general health

developed to form viable therapeutic options. For example, active ingredients in Rhizoma polygonati, an herb in traditional Chinese medicine, were screened from various databases to find 23 targets were found in SARS$\mathrm{CoV}-2$ by active ingredients [162]. Additionally, ten active compounds in Rhizoma Polygonati had good molecular docking scores with different drug targets of SARSCoV-2 such as ACE2, 3CL hydrolase, Spike protein S1, and RNA-dependent RNA polymerase RdRp. Also, active compounds of Stingless bee honey demonstrate antibacterial activity (preventing secondary bacterial infection), antioxidant properties (reducing oxidative stress) and downregulation of IL-6 (shortening viral endurance in the body) [163]. Foods like this can be developed into novel functional foods through rigorous testing of efficacy, safety, and toxicity to produce viable, effective therapeutic options for COVID-19 infections.

\section{Conclusions}

More than two years have progressed since the first case of the pandemic was contracted in Wuhan. Many countries are already experiencing multiple waves of COVID19 with increasing strains on the health care system. As of June 2021, vaccines for COVID-19 have already been approved and distributed to millions of people worldwide, which has gradually reduced the infection rates in specific countries. However, the deployment of COVID19 vaccines has raised concerns over equal, just access of different individuals to such an essential health care service. In December 2020, 51\% of all vaccine doses were purchased by high-income countries that represent only $14 \%$ of the world population [164]. By April 2021, about 1 in 4 people were vaccinated in high-income countries compared to 1 in more than 500 in low-income countries [165]. 


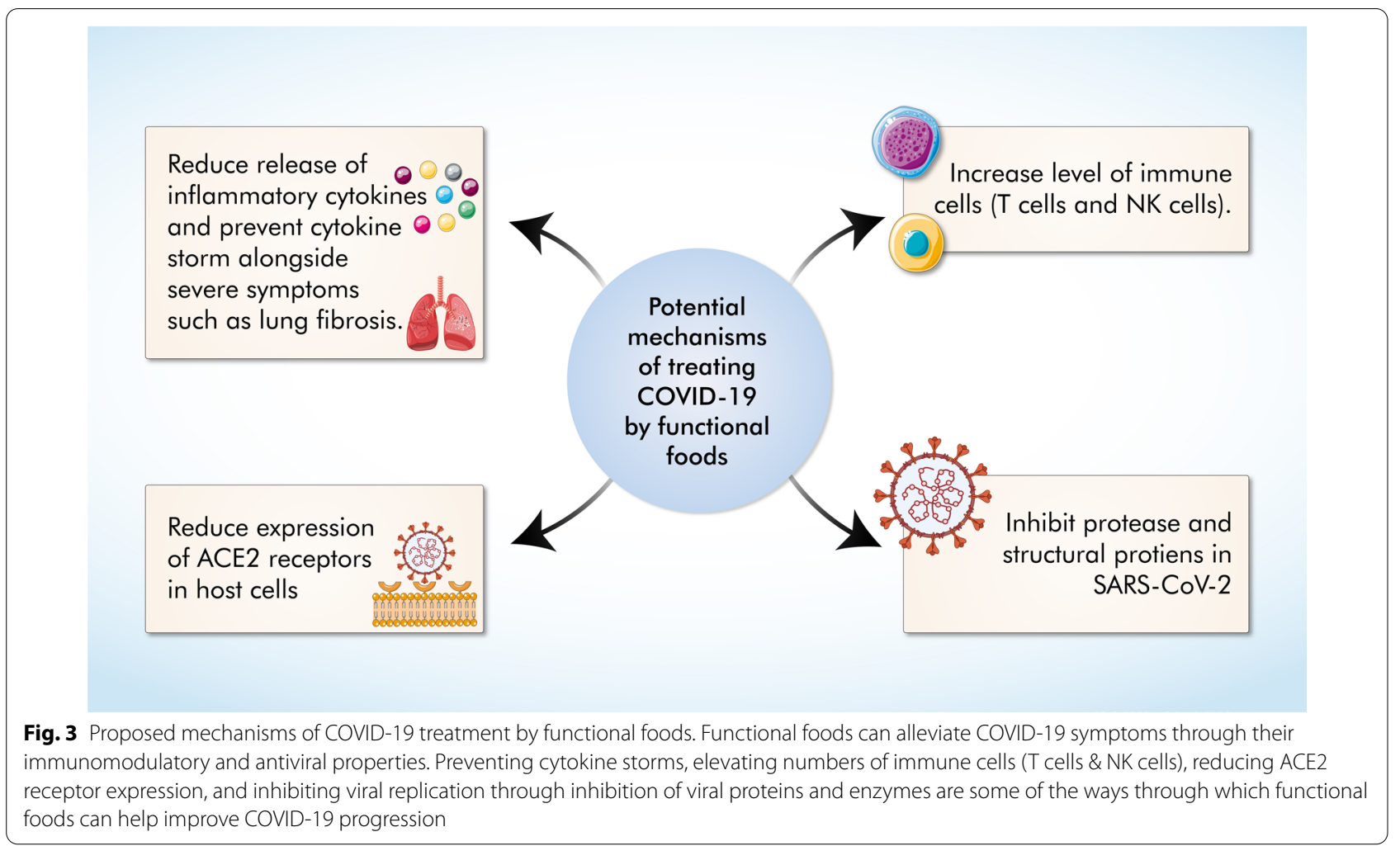

Additionally, vaccines have been reported to have a low incidence of severe side effects in the population, such as Guillain-Barre syndrome (GBS), blood clots, and heart muscle inflammation [166]. Although such instances are rare, they have made the headlines that have instilled fear in many individuals who have become hesitant to receive the vaccine. Furthermore, antiviral drugs such as Remdesivir, which are used to treat COVID-19 infections, have harmful side effects that prolong the suffering of patients (Table 4). Therefore, until sufficient vaccines are supplied, alternative therapeutic options through functional foods must be employed. However, prescription of the diet with functional foods needs to consider toxicology studies as well. Toxicological evaluations reveal the necessity of further safety tests of different functional foods and standardizing their levels in a regular diet with the latest research data is essential. Furthermore, as the dosage of functional food has different effects on pre-existing conditions, specific safety levels for such individuals must be evaluated. Alongside functional foods, healthy lifestyle choices and regular exercises (that strengthen the immune system) can significantly reduce the financial strain of COVID-19, suffering of patients and death rates across the globe during this pandemic.

\section{Acknowledgements}

The authors acknowledge the members of the Community of Biotechnology, Dhaka, Bangladesh, for their support during the preparation of the manuscript.

\section{Authors' contributions}

MH conceived the study. SS, MF, YA, JT, AC, TN, KM, TR, and MH designed the study. MF and SS wrote the draft manuscript. MH, YA, MU, SS, and MF carried out the revisions. All authors read and approved the final manuscript.

\section{Funding}

The authors received no funding from external sources.

Availability of data and materials

Not applicable.

\section{Declarations}

Ethics approval and consent to participate

Not applicable.

\section{Consent for publication}

Not applicable.

\section{Competing interests}

The authors declare that they have no known competing financial interests or personal relationships that could have appeared to influence the work reported in this paper.

\section{Author details}

'Biotechnology Program, Department of Mathematics and Natural Sciences, School of Data and Sciences, Brac University, Dhaka, Bangladesh. ${ }^{2}$ Department of Genetic Engineering and Biotechnology, School of Life Sciences, Shahjalal University of Science and Technology, Sylhet, Bangladesh. ${ }^{3}$ Department 
of Biotechnology and Genetic Engineering, Faculty of Biological Sciences, Jahangirnagar University, Savar, Dhaka, Bangladesh. ${ }^{4}$ Department of Pharmacy, Faculty of Biological Sciences, University of Chittagong, Chattogram, Bangladesh. ${ }^{5}$ Department of Biotechnology and Genetic Engineering, Faculty of Life Sciences, Bangabandhu Sheikh Mujibur Rahman Science and Technology University, Gopalganj, Bangladesh.

Received: 16 December 2021 Accepted: 18 February 2022

Published online: 07 March 2022

References (Papers of particular interest, published recently, have been highlighted as: • Of importance; •• Of major importance)

1. Araf Y, Faruqui NA, Anwar S et al (2021) SARS-CoV-2: a new dimension to our understanding of coronaviruses. Int Microbiol 24:19-24. https:// doi.org/10.1007/s10123-020-00152-y

2. COVID Live Update [Internet]. Worldometers.info. 2022 [cited 10 February 2022]. https://www.worldometers.info/coronavirus/

3. Araf Y, Akter F, Tang YD, Fatemi R, Parvez MSA, Zheng C, Hossain MG (2022) Omicron variant of SARS-CoV-2: genomics, transmissibility, and responses to current COVID-19 vaccines. J Med Virol. https://doi.org/10. 1002/jmv.27588

4. COVID-19 vaccine tracker [Internet]. Raps.org. 2021 [cited 22 March 2021]. https://www.raps.org/news-and-articles/news-articles/2020/3/ covid-19-vaccine-tracker

5. McCarthy N. Infographic: How effective are the Covid-19 vaccines? [Internet]. Statista Infographics. 2021 [cited 22 March 2021]. https:// www.statista.com/chart/23510/estimated-effectiveness-of-covid-19vaccine-candidates/

6. Coronavirus (COVID-19) Vaccinations-Statistics and Research [Internet]. Our World in Data. 2021 [cited 10 Feb 2022]. https://ourworldin data.org/covid-vaccinations

7. Mahmoud A (2016) New vaccines: challenges of discovery. Microb Biotechnol 9(5):549-552

8. Hui D, Lee N, Chan P (2017) A clinical approach to the threat of emerging influenza viruses in the Asia-Pacific region. Respirology 22(7):1300-1312

9. Cao Y, Deng Q, Dai S (2020) Remdesivir for severe acute respiratory syndrome coronavirus 2 causing COVID-19: an evaluation of the evidence. Travel Med Infect Dis 35:101647

10. Grein J, Ohmagari N, Shin D, Diaz G, Asperges E, Castagna A et al (2020) Compassionate use of Remdesivir for patients with severe Covid-19. N Engl J Med 382(24):2327-2336

11. Shaw M (2017) The next wave of influenza drugs. ACS Infect Dis 3(10):691-694

12. ..Yang F, Zhang Y, Tariq A, Jiang X, Ahmed Z, Zhihao Z et al (2020) Food as medicine: a possible preventive measure against coronavirus disease (COVID-19). Phytother Res 34(12):3124-3136. The review has mentioned several important functional food plants with immunomodulatory and anti-viral properties that can be used to treat COVID-19. It has also suggested that functional foods can be a superior alternative for all the drugs designed for rapidly changed strains of the coronavirus

13. -Alkhatib A (2020) Antiviral functional foods and exercise lifestyle prevention of coronavirus. Nutrients 12(9):2633. The review displayed great roles of functional foods including antiviral activities, synthesizing active agents, and modulating the immune system against the COVID-19. It mentioned the nutraceutical properties of several fruits, vegetables, fermented foods, and probiotics

14. García, (2020) Immune response, inflammation, and the clinical spectrum of COVID-19. Front Immunol 6:66

15. Groeneveld A (2002) Vascular pharmacology of acute lung injury and acute respiratory distress syndrome. Vas Pharmacol 39(4-5):247-256

16. Paces J, Strizova Z, Smrz D, Cerny J (2020) COVID-19 and the immune system. Physiol Res 69(3):379-388

17. Fung T, Liu D (2020) Human coronavirus: host-pathogen interaction. Annu Rev Microbiol 73(1):529-557

18. Prompetchara E, Ketloy C, Palaga T (2020) Immune responses in COVID-19 and potential vaccines: lessons learned from SARS and MERS epidemic. Asian Pac J Allergy Immunol 38(1):1-9
19. Hur S (2019) Double-stranded RNA sensors and modulators in innate immunity. Annu Rev Immunol 37(1):349-375

20. Dandekar A, Perlman S (2005) Immunopathogenesis of coronavirus infections: implications for SARS. Nat Rev Immunol 5(12):917-927

21. Chen J, Subbarao K (2007) The immunobiology of SARS. Annu Rev Immunol 25(1):443-472

22. Barnes B, Adrover J, Baxter-Stoltzfus A, Borczuk A, Cools-Lartigue J Crawford J et al (2020) Targeting potential drivers of COVID-19: neutrophil extracellular traps. J Exp Med 217(6):66

23. Tay M, Poh C, Rénia L, MacAry P, Ng L (2020) The trinity of COVID19: immunity, inflammation and intervention. Nat Rev Immunol 20(6):363-374

24. Soy M, Keser G, Atagündüz P, Tabak F, Atagündüz I, Kayhan S (2020) Cytokine storm in COVID-19: pathogenesis and overview of anti-inflammatory agents used in treatment. Clin Rheumatol 39(7):2085-2094

25. Butnariu M, Sarac I (2019) Functional food. Int J Nutr 3(3):7-16

26. Aparicio-Soto M, Sánchez-Hidalgo M, Rosillo M, Castejón M, Alarcónde-la-Lastra C (2016) Extra virgin olive oil: a key functional food for prevention of immune-inflammatory diseases. Food Funct 7(11):4492-4505

27. Gombart A, Pierre A, Maggini S (2020) A review of micronutrients and the immune system-working in harmony to reduce the risk of infection. Nutrients 12(1):236

28. Dawson M (2000) The importance of vitamin A in nutrition. Curr Pharm Des 6(3):311-325

29. Singer J, Bakall B, Gordon G, Reddy R (2016) Treatment of vitamin A deficiency retinopathy with sublingual vitamin A palmitate. Documenta Ophthalmologica 132(2):137-145. https://doi.org/10.1007/ s10633-016-9533-2

30. Robertson T, Alzaabi A, Robertson M, Fielding B (2018) Starchy carbohydrates in a healthy diet: the role of the humble potato. Nutrients 10(11):1764

31. Brown M, Ameer M, Beier K. Vitamin B6 deficiency (pyridoxine). Ncbi. nlm.nih.gov. 2020. https://www.ncbi.nlm.nih.gov/books/NBK470579/

32. Steluti J, Martini L, Peters B, Marchioni D (2011) Folate, vitamin B6 and vitamin B12 in adolescence: serum concentrations, prevalence of inadequate intakes and sources in food. Jornal de Pediatria 87(1):43-49

33. Sinbad O, Folorunsho A, Olabisi O, Ayoola O, Temitope E (2019) Vitamins as antioxidants. J Food Sci Nutr Res 2:214-235

34. Hellmann H, Mooney S (2010) Vitamin B6: a molecule for human health? Molecules 15(1):442-459

35. Roje S (2007) Vitamin B biosynthesis in plants. Phytochemistry 68(14):1904-1921

36. Watanabe F (2007) Vitamin B12 sources and bioavailability. Exp Biol Med 232(10):1266-1274

37. Subar A, Block G, James L (1989) Folate intake and food sources in the US population. Am J Clin Nutr 50(3):508-516

38. Witthöft C, Forssén K, Johannesson L, Jägerstad M (1999) Folatesfood sources, analyses, retention and bioavailability. Näringsforskning 43(1):138-146. https://doi.org/10.3402/fnr.v43i0.1771

39. Ebara S (2017) Nutritional role of folate. Congenital anomalies 57(5):138-141

40. Carr A, Maggini S (2017) Vitamin C and immune function. Nutrients 9(11):1211

41. Basu A, Nguyen A, Betts N, Lyons T (2013) Strawberry as a functional food: an evidence-based review. Crit Rev Food Sci Nutr 54(6):790-806

42. Granger M, Eck P (2018) Dietary vitamin C in human health. Adv Food Nutr Res 83:281-310

43. Van der Velden U (2020) Vitamin C and its role in periodontal diseasesthe past and the present: a narrative review. Oral Health Prev Dent 18(2):115-124

44. Lamberg-Allardt C (2006) Vitamin D in foods and as supplements. Prog Biophys Mol Biol 92(1):33-38

45. Traber M, Packer L (1995) Vitamin E: beyond antioxidant function. Am J Clin Nutr 62(6):1501S-1509S

46. Wang $X$, Quinn $P(2000)$ The location and function of vitamin $E$ in membranes (review). Mol Membr Biol 17(3):143-156

47. Wada O (2004) What are trace elements? Their deficiency and excess states. Jpn Med Assoc J 47(8):351-358 
48. Rubio C, Gutiérrez Á, Revert C, Reguera J, Burgos A, Hardisson A (2009) Daily dietary intake of iron, copper, zinc and manganese in a Spanish population. Int J Food Sci Nutr 60(7):590-600

49. Kieliszek M (2019) Selenium-fascinating microelement, properties and sources in food. Molecules 24(7):1298

50. Razzaque M (2018) Magnesium: Are we consuming enough? Nutrients 10(12):1863

51. Nasri H, Baradaran A, Shirzad H, Rafieian-Kopaei M (2014) New concepts in nutraceuticals as alternative for pharmaceuticals. Int J Prev Med 5(12):1487-1499

52. Keservani R, Kesharwani R, Vyas N, Jain S, Raghuvanshi R, Sharma A (2010) Nutraceutical and functional food as future food: a review. Pharm Lett 2(1):106-116

53. Lentjes M, Welch A, Mulligan A, Luben R, Wareham N, Khaw K (2014) Cod liver oil supplement consumption and health: cross-sectional results from the EPIC-Norfolk cohort study. Nutrients 6(10):4320-4337

54. Riaz M, Rahman N, Zia-Ul-Haq M, Jaffar H, Manea R (2019) Ginseng: a dietary supplement as immune-modulator in various diseases. Trends Food Sci Technol 83:12-30

55. Lye H, Balakrishnan K, Thiagarajah K, Mohd Ismail N, Ooi S (2016) Beneficial properties of probiotics. Trop Life Sci Res 27(2):73-90

56. Vlasova A, Takanashi S, Miyazaki A, Rajashekara G, Saif L (2019) How the gut microbiome regulates host immune responses to viral vaccines. Curr Opin Virol 37:16-25

57. •.Yang F, Zhang Y, Tariq A, Jiang X, Ahmed Z, Zhihao Z et al (2020) Food as medicine: a possible preventive measure against coronavirus disease (COVID -19). Phytother Res. https://doi.org/10.1002/ptr.6770. This extensive systematic review of various functional foods focuses on specific immunomodulatory and antimicrobial properties amongst other benefits investigated in different studies. The multitude of studies mentioned has provided sufficient evidence for the proven assistance of these foods in boosting the immune system with additional health benefits

58. Santiago-López L, Hernández-Mendoza A, Vallejo-Cordoba B, MataHaro V, González-Córdova A (2016) Food-derived immunomodulatory peptides. J Sci Food Agric 96(11):3631-3641

59. Chandra R. Nutrition and the immune system: an introduction. The American Journal of Clinical Nutrition [Internet]. 1997 [cited 3 October 2020];66(2):460S-463S. Available from: https://pubmed.ncbi.nlm.nih. gov/9250133/

60. Shi L, Zhang L, Li C, Hu X, Wang X, Huang Q et al (2016) Dietary zinc deficiency impairs humoral and cellular immune responses to BCG and ESAT-6/CFP-10 vaccination in offspring and adult rats. Tuberculosis 97:86-96

61. Axelrod A (1971) Immune processes in vitamin deficiency states. Am J Clin Nutr 24(2):265-271

62. Cinatl J, Morgenstern B, Bauer G, Chandra P, Rabenau H, Doerr H (2003) Glycyrrhizin, an active component of liquorice roots, and replication of SARS-associated coronavirus. The Lancet 361(9374):2045-2046

63. Zhong Y, Ma C, Shahidi F (2012) Antioxidant and antiviral activities of lipophilic epigallocatechin gallate (EGCG) derivatives. J Funct Foods 4(1):87-93

64. Mohamed S, Hashim S, Rahman H (2012) Seaweeds: a sustainable functional food for complementary and alternative therapy. Trends Food Sci Technol 23(2):83-96

65. Gupta S, Kapur S, Padmavathi D, Verma A (2015) Garlic: an effective functional food to combat the growing antimicrobial resistance. Pertanika J Trop Agric Sci 38(2):271-278

66. Shannon E, Abu-Ghannam N (2016) Antibacterial derivatives of marine algae: an overview of pharmacological mechanisms and applications. Marine Drugs 14(4):81

67. Dorsaz S, Snäkä T, Favre-Godal Q, Maudens P, Boulens N, Furrer P et al (2017) Identification and mode of action of a plant natural product targeting human fungal pathogens. Antimicrob Agents Chemother 61(9):829-17

68. Kumar K (2015) Role of edible mushrooms as functional foods-a review. South Asian J Food Technol Environ 1(3\&4):211-218

69. Nimalaratne C, Wu J (2015) Hen egg as an antioxidant food commodity: a review. Nutrients 7(10):8274-8293
70. Zhao X, Feng X, Wang C, Peng D, Zhu K, Song J (2016) Anticancer activity of Nelumbo nucifera stamen extract in human colon cancer HCT-116 cells in vitro. Oncol Lett 13(3):1470-1478

71. José Bagur M, Alonso Salinas G, Jiménez-Monreal A, Chaouqi S, Llorens S, Martínez-Tomé M et al. Saffron: An Old Medicinal Plant and a Potential Novel Functional Food. Molecules [Internet]. 2017 [cited 3 October 2020];23(1):30. Available from: https://www.ncbi.nlm.nih.gov/pmc/artic les/PMC5943931/

72. VoT, Ngo D (2019) The health beneficial properties of rhodomyrtus tomentosa as potential functional food. Biomolecules 9(2):76

73. Deepak M, Handa S (2000) Antiinflammatory activity and chemical composition of extracts of Verbena officinalis. Phytother Res 14(6):463-465

74. lahtisham-Ul-Haq Butt M, Randhawa M, Shahid M (2019) Nephroprotective effects of red beetroot-based beverages against gentamicininduced renal stress. J Food Biochem 43(7):66. https://doi.org/10.1111/ jfbc. 12873

75. Ben Saad A, Ncib S, Rjeibi I, Saidi I, Zouari N (2019) Nephroprotective and antioxidant effect of green tea (Camellia sinensis) against nicotineinduced nephrotoxicity in rats and characterization of its bioactive compounds by HPLC-DAD. Appl Physiol Nutr Metab 44(11):1134-1140

76. Asselah T, Durantel D, Pasmant E, Lau G, Schinazi R (2020) COVID-19: discovery, diagnostics and drug development. J Hepatol 74(1):168-184

77. Wang M, Cao R, Zhang L, Yang X, Liu J, Xu M et al (2020) Remdesivir and chloroquine effectively inhibit the recently emerged novel coronavirus (2019-nCoV) in vitro. Cell Res 30(3):269-271

78. Beigel J, Tomashek K, Dodd L, Mehta A, Zingman B, Kalil A et al (2020) Remdesivir for the treatment of Covid-19_final report. N Engl J Med 383(19):1813-1826

79. Devaux C, Rolain J, Colson P, Raoult D (2020) New insights on the antiviral effects of chloroquine against coronavirus: What to expect for COVID-19? Int J Antimicrob Agents 55(5):105-938

80. Gao J, Tian Z, Yang X (2020) Breakthrough: Chloroquine phosphate has shown apparent efficacy in treatment of COVID-19 associated pneumonia in clinical studies. Biosci Trends 14(1):72-73

81. Huang M, Tang T, Pang P, Li M, Ma R, Lu J et al (2020) Treating COVID-19 with Chloroquine. J Mol Cell Biol 12(4):322-325

82. Cao B, Wang Y, Wen D, Liu W, Wang J, Fan G et al (2020) A trial of Lopinavir-Ritonavir in adults hospitalized with severe Covid-19. N Engl J Med 382(19):1787-1799

83. Stower H (2020) Lopinavir-ritonavir in severe COVID-19. Nat Med 26(4):465-465

84. Common and Rare Side Effects for lopinavir-ritonavir oral [Internet]. Webmd.com. 2021 [cited 22 March 2021]. https://www.webmd.com/ drugs/2/drug-19938-3294/lopinavir-ritonavir-oral/lopinavir-ritonavirsolution-oral/details/list-sideeffects

85. Cai Q, Yang M, Liu D, Chen J, Shu D, Xia J et al (2020) Experimental treatment with Favipiravir for COVID-19: an open-label control study. Engineering 6(10):1192-1198

86. Dong L, Hu S, Gao J (2020) Discovering drugs to treat coronavirus disease 2019 (COVID-19). Drug Discov Therap 14(1):58-60

87. Kaur R, Charan J, Dutta S, Sharma P, Bhardwaj P, Sharma P et al (2020) Favipiravir use in COVID-19: analysis of suspected adverse drug events reported in the WHO database. Infect Drug Resist 13:4427-4438

88. Favalli E, Biggioggero M, Maioli G, Caporali R (2020) Baricitinib for COVID-19: a suitable treatment? Lancet Infect Dis 20(9):1012-1013

89. Common and Rare Side Effects for baricitinib oral [Internet]. Webmd. com. 2021 [cited 22 March 2021]. https://www.webmd.com/drugs/2/ drug-174071/baricitinib-oral/details/list-sideeffects

90. Mishra S, Tripathi T (2021) One year update on the COVID-19 pandemic: Where are we now? Acta Tropica 214:105778

91. Vaccines and Related Biological Products Advisory Committee Meeting [Internet]. Fda.gov. 2021 [cited 22 March 2021]

92. Information about the Pfizer-BioNTech COVID-19 Vaccine. Centers for Disease Control and Prevention. 2021. [cited 22 March 2021].

93. Sah R, Shrestha S, Mehta R, Sah S, Rabaan A, Dhama K et al (2021) AZD1222 (Covishield) vaccination for COVID-19: experiences, challenges, and solutions in Nepal. Travel Med Infect Dis 40:101989

94. Baraniuk C (2021) Covid-19: What do we know about Sputnik V and other Russian vaccines? BMJ 66:743 
95. Li Y, Liu S, Zhang S, Ju Q, Zhang S, Yang Y et al (2020) Current treatment approaches for COVID-19 and the clinical value of transfusion-related technologies. Transfusion Apheresis Sci 59(5):102839

96. Mair-Jenkins J, Saavedra-Campos M, Baillie J, Cleary P, Khaw F, Lim W et al (2014) The effectiveness of convalescent plasma and hyperimmune immunoglobulin for the treatment of severe acute respiratory infections of viral etiology: a systematic review and exploratory metaanalysis. J Infect Dis 211(1):80-90

97. Cheng Y, Wong R, Soo Y, Wong W, Lee C, Ng M et al (2004) Use of convalescent plasma therapy in SARS patients in Hong Kong. Eur J Clin Microbiol Infect Dis 24(1):44-46

98. Tsang K, Zhong N (2003) SARS: pharmacotherapy. Respirology 8(s1):S25-S30

99. Li Z, Teng B, Luo J, Zhao J (2010) Clinical application of therapeutic plasma exchange in the Three Gorges Area. Transfus Apheres Sci 43(3):305-308

100. Bellagamba B, Abreu B, Grivicich I, Markarian C, Chem E, Camassola M et al (2016) Human mesenchymal stem cells are resistant to cytotoxic and genotoxic effects of cisplatin in vitro. Genet Mol Biol 39(1):129-134

101. Barkholt L, Flory E, Jekerle V, Lucas-Samuel S, Ahnert P, Bisset L et al (2013) Risk of tumorigenicity in mesenchymal stromal cell-based therapies-bridging scientific observations and regulatory viewpoints. Cytotherapy 15(7):753-759

102. Cherry J, Harrison G, Kaplan S, Steinbach W, Hotez P. Feigin and Cherry's textbook of pediatric infectious diseases e-book.

103. Stratton R (2005) Should food or supplements be used in the community for the treatment of disease-related malnutrition? Proc Nutr Soc 64(3):325-333

104. Alkhatib A, Tsang C, Tiss A, Bahorun T, Arefanian H, Barake R et al (2017) Functional foods and lifestyle approaches for diabetes prevention and management. Nutrients 9(12):1310

105. Planas M, Álvarez J, García-Peris P, de la Cuerda C, de Lucas P, Castellà M et al (2005) Nutritional support and quality of life in stable chronic obstructive pulmonary disease (COPD) patients. Clin Nutr 24(3):433-441

106. Sugawara K, Takahashi H, Kasai C, Kiyokawa N, Watanabe T, Fujii S et al (2010) Effects of nutritional supplementation combined with low-intensity exercise in malnourished patients with COPD. Respir Med 104(12): 1883-1889

107. Agler A, Kurth T, Gaziano J, Buring J, Cassano P (2011) Randomised vitamin E supplementation and risk of chronic lung disease in the Women's Health Study. Thorax 66(4):320-325

108. Lehouck A, Mathieu C, Carremans C, Baeke F, Verhaegen J, Van Eldere J et al (2012) High doses of vitamin D to reduce exacerbations in chronic obstructive pulmonary disease. Ann Intern Med 156(2):105

109. Butland B (2000) Diet, lung function, and lung function decline in a cohort of 2512 middle aged men. Thorax 55(2):102-108

110. Dow L, Tracey M, Villar A, Coggon D, Margetts B, Campbell M et al (1996) Does dietary intake of vitamins $C$ and $E$ influence lung function in older people? Am J Respir Crit Care Med 154(5):1401-1404

111. Schwartz J, Weiss S (1994) Relationship between dietary vitamin C intake and pulmonary function in the First National Health and Nutrition Examination Survey (NHANES I). Am J Clin Nutr 59(1):110-114

112. Britton J, Pavord I, Richards K, Knox A, Wisniewski A, Lewis S et al (1995) Dietary antioxidant vitamin intake and lung function in the general population. Am J Respir Crit Care Med 151(5):1383-1387

113. Guenegou A, Boczkowski J, Aubier M, Neukirch F, Leynaert B (2007) Interaction between a heme oxygenase-1 gene promoter polymorphism and serum-carotene levels on 8-year lung function decline in a general population: the European Community Respiratory Health Survey (France). Am J Epidemiol 167(2):139-144

114. Ochs-Balcom H, Grant B, Muti P, Sempos C, Freudenheim J, Browne $R$ et al (2006) Antioxidants, oxidative stress, and pulmonary function in individuals diagnosed with asthma or COPD. Eur J Clin Nutr 60(8):991-999

115. Velez E, Maldonado Galdeano C, Carmuega E, Weill R, Bibas Bonet M, Perdigón G (2015) Probiotic fermented milk consumption modulates the allergic process induced by ovoalbumin in mice. Br J Nutr 114(4):566-576

116. Abad M, Guerra J, Bermejo P, Irurzun A, Carrasco L (2000) Search for antiviral activity in higher plant extracts. Phytother Res 14(8):604-607
117. ..Alagu Lakshmi S, Shafreen R, Priya A, Shunmugiah K., 2020. Ethnomedicines of Indian origin for combating COVID-19 infection by hampering the viral replication: using structure-based drug discovery approach. J Biomol Struct Dyn 1-16. In this study interaction of the active components from 10 different medicinal plants of Indian origin was determined through molecular docking analysis. Plant-based phenolic compounds from medicinal plants such as Dioscorea batatas, Glycyrrhiza radix, Mollugo cerviana, Polygonum multiflorum Thunb and many more were shown to be active against coronaviruses

118. Lau K, Lee K, Koon C, Cheung C, Lau C, Ho H et al (2008) Immunomodulatory and anti-SARS activities of Houttuynia cordata. J Ethnopharmacol 118(1):79-85

119. Ding Y, Zeng L, Li R, Chen Q, Zhou B, Chen Q et al (2017) The Chinese prescription lianhuaqingwen capsule exerts anti-influenza activity through the inhibition of viral propagation and impacts immune function. BMC Complement Altern Med 17(1):66

120. • Yang Y, Islam M, Wang J, Li Y, Chen X., 2020. Traditional Chinese Medicine in the treatment of patients infected with 2019-new coronavirus (SARS-CoV-2): a review and perspective. Int J Biol Sci 16(10):1708-1717. This review and perspective provided an insight into the mechanism underlying the therapeutic effect of Traditional Chinese Medicine treatments. A Chinese plant named Lianhuaqingwen was proved to have antiviral activities against several COVID-19 symptoms, such as fever, cough, fatigue, influenza, bronchitis, and pneumonia

121. Sharifi N, Souri E, Ziai S, Amin G, Amanlou M (2013) Discovery of new angiotensin converting enzyme (ACE) inhibitors from medicinal plants to treat hypertension using an in vitro assay. DARU J Pharm Sci 21(1):66

122. Fedoreyev S, Krylova N, Mishchenko N, Vasileva E, Pislyagin E, lunikhina $O$ et al (2018) Antiviral and antioxidant properties of echinochrome A. Mar Drugs 16(12):509

123. · Benarba B, Pandiella A (2020) Medicinal plants as sources of active molecules against COVID-19. Front Pharmacol 11. In this review the recent findings regarding the use of natural products to prevent or treat COVID-19 infection has been identified, which showed effective against SARS-CoV-2 actions by direct inhibition of the virus replication or entry. These functional foods were also showed to inhibit the coronavirus related proteins such as papain-like or chymotrypsin-like proteases

124. Donma M, Donma O (2020) The effects of allium sativum on immunity within the scope of COVID-19 infection. Med Hypoth 144:109-934

125. ..Subhrajyoti C, Shalini (2020) Immunomodulatory herbs of Ayurveda and Covid-19: a review article. J Ayurveda Integr Med Sci 5(2):203-208. https://www.jaims.in/jaims/article/view/886. This review from the Journal of Ayurveda and Integrated Medical Sciences provides detailed accounts of different common herbs, their bioactive constituents, and numerous beneficial properties. The myriad of information collected from this article provided essential characteristics of the different herbs outlined in tabular format

126. ..Gyawali R, Paudel P, Basyal D, Setzer W, Lamichhane S, Paudel M, Gyawali S, Khanal Prajwal (2020) A review on ayurvedic medicinal herbs as remedial prospective for COVID-19. JKAHS 3(special issue). https:// jkahs.org.np/jkahs/index.php/jkahs/article/view/237/156. This review article outlined bioactive compounds and antiviral properties of different medicinal herbs with the aim to intervene SARS-CoV-2 through similar antiviral mechanisms. The comprehensive process given for each herb highlights the antiviral aspects of functional foods and their immense potential in treatment \& management of viral infections

127. Pandey P, Khan F, Kumar A, Srivastava A, Jha N (2020) Screening of potent inhibitors against 2019 novel coronavirus (Covid-19) from Alliumsativum and Allium cepa: an in silico approach. Biointerface Res Appl Chem 11(1):7981-7993

128. Hasler C (1998) Functional foods: their role in disease prevention and health promotion. Food Technol 52:63-70

129. Mao Q, Xu X, Cao S, Gan R, Corke H, Beta T et al (2019) bioactive compounds and bioactivities of ginger (Zingiber officinale Roscoe). Foods 8(6):185

130. Rajagopal K, Bryan G, Jupudi S, Vadivelan R (2020) Activity of phytochemical constituents of black pepper, ginger, and garlic against coronavirus (COVID-19): an in silico approach. Int J Health Allied Sci 9(5):43-50 
131. Niranjan A, Prakash D (2008) Chemical constituents and biological activities of turmeric (Curcuma longa L.) —a review. J Food Sci Technol 45(2):109-116

132. · Kunnumakkara A, Rana V, Parama D, Banik K, Girisa S, Sahu H et al (20201) COVID-19, cytokines, inflammation, and spices: How are they related? Life Sci 119201. This systemic review provides an overall picture of the origin of COVID-19 infection, its mechanism alongside conventional drugs used for its management and the anti-inflammatory role of spices to prevent the cytokine storm caused by SARS-CoV-2. The mechanism by which spices can attenuate COVID-19 associated cytokine storm revealed potential health benefits for COVID-19 patients from consumption of different spices

133. Deutch M, Grimm D, Wehland M, Infanger M, Krüger M (2019) Bioactive candy: effects of licorice on the cardiovascular system. Foods 8(10):495

134. Murck H (2020) symptomatic protective action of glycyrrhizin (Licorice) in COVID-19 infection? Front Immunol 11:66

135. Desai A, Desai C, Desai H, Mansuri A, Desai J (2020) Possible role of medicinal plants in Covid19_a brief review. Int J Sci Dev Res 5(4):205-209

136. Akhtar M, Swamy M, Sinniah U (2019) Natural bio-active compounds. Springer, Singapore

137. Baildya N, Khan A, Ghosh N, Dutta T, Chattopadhyay A (2021) Screening of potential drug from Azadirachta Indica (Neem) extracts for SARSCoV-2: an insight from molecular docking and MD-simulation studies. J Mol Struct 1227:129390

138. ..Shree P, Mishra P, Selvaraj C, Singh S, Chaube R, Garg N et al., 2020. Targeting COVID-19 (SARS-CoV-2) main protease through active phytochemicals of ayurvedic medicinal plants -Withania somnifera(As hwagandha),Tinospora cordifolia(Giloy) andOcimum sanctum(Tulsi) - a molecular docking study. J Biomol Struct Dyn 1-14. https://doi.org/ 10.1080/07391102.2020.1810778. This molecular docking study investigated natural phytochemicals present in three different medicinal plants in order to determine potential inhibitors of the main protease of SARS-CoV-2. The results of the study revealed numerous probable inhibitors from the plants that could bind to the protease, were safe and had drug-like properties. The data from this study provided concrete grounds to suggest further investigation with these phytochemicals to extract the antiviral properties against SARS-CoV-2

139. Siva M, Shanmugam KR, Shanmugam B, Venkata G, Sahukari R, Sathyavelu K et al (2016) Ocimum sanctum: a review on the pharmacological properties. Int J Basic Clin Pharmacol 66:558-565

140. Salehi B, Zakaria Z, Gyawali R, Ibrahim S, Rajkovic J, Shinwari Z et al (2019) Piper species: a comprehensive review on their phytochemistry. Biol Activities Appl Mol 24(7):1364

141. Rao P, Gan S (2014) Cinnamon: a multifaceted medicinal plant. Evid Based Complement Altern Med 66:1-12

142. Teshika J, Zakariyyah A, Zaynab T, Zengin G, Rengasamy K, Pandian S et al (2018) Traditional and modern uses of onion bulb (Allium cepa L.) a systematic review. Crit Rev Food Sci Nutr 59(sup1):S39-S70

143. Thota S, Balan V, Sivaramakrishnan V (2020) Natural products as homebased prophylactic and symptom management agents in the setting of COVID-19. Phytother Res 34(12):3148-3167

144. Prasanth M, Sivamaruthi B, Chaiyasut C, Tencomnao T (2019) A review of the role of Green Tea (Camellia sinensis) in antiphotoaging, stress resistance, neuroprotection, and autophagy. Nutrients 11(2):474

145. Mhatre S, Srivastava T, Naik S, Patravale V (2021) Antiviral activity of green tea and black tea polyphenols in prophylaxis and treatment of COVID-19: a review. Phytomedicine 85:153286

146. Townsend E, Siviski M, Zhang Y, Xu C, Hoonjan B, Emala C (2013) Effects of ginger and its constituents on airway smooth muscle relaxation and calcium regulation. Am J Respir Cell Mol Biol 48(2):157-163

147. Weir E, Thenappan T, Bhargava M, Chen Y (2020) Does vitamin D deficiency increase the severity of COVID-19? Clin Med 20(4):e107-e108

148. Grant W, Lahore H, McDonnell S, Baggerly C, French C, Aliano J et al (2020) Evidence that vitamin D supplementation could reduce risk of influenza and COVID-19 infections and deaths. Nutrients 12(4):988

149. Rahman M, Idid S (2020) Can Zn be a critical element in COVID-19 treatment? Biol Trace Elem Res 199(2):550-558

150. Kubin C, McConville T, Dietz D, Zucker J, May M, Nelson B et al (2021) Characterization of bacterial and fungal infections in hospitalized patients with coronavirus disease 2019 and factors associated with health care-associated infections. Open Forum Infect Dis 8(6):66

151. Vijay S, Bansal N, Rao B, Veeraraghavan B, Rodrigues C, Wattal C et al (2021) Secondary infections in hospitalized COVID-19 patients: indian experience. Infect Drug Resist 14:1893-1903

152. Goncagul G, Ayaz E (2010) Antimicrobial effect of Garlic (Allium sativum). Recent Pat Anti-Infect Drug Discov 5(1):91-93

153. Xie J, Yao M, Lu Y, Yu M, Han S, McClements D et al (2021) Impact of encapsulating a probiotic (Pediococcus pentosaceus Li05) within gastroresponsive microgels on Clostridium difficile infections. Food Funct 12(7):3180-3190

154. Bousquet J, Czarlewski W, Zuberbier T, Mullol J, Blain H, Cristol J et al (2020) Spices to control COVID-19 symptoms: yes, but not only.... Int Arch Allergy Immunol 182(6):489-495

155. Bousquet J, Le Moing V, Blain H, Czarlewski W, Zuberbier T, de la Torre R et al (2021) Efficacy of broccoli and glucoraphanin in COVID-19: From hypothesis to proof-of-concept with three experimental clinical cases. World Allergy Organ J 14(1):100498

156. Silva Andrade B, Siqueira S, de Assis SW, de Souza RF, Santos N, dos Santos FA et al (2021) Long-COVID and post-COVID health complications: an up-to-date review on clinical conditions and their possible molecular mechanisms. Viruses 13(4):700

157. Han B, Hoang B (2021) Opinions on the current pandemic of COVID-19: use functional food to boost our immune functions. J Infect Public Health 13(12):1811-1817

158. Korkmaz H (2020) Could sumac be effective on COVID-19 treatment? J Med Food 6:66

159. Venkateswaran M, Jayabal S, Hemaiswarya S, Murugesan S, Enkateswara S, Doble M et al (2021) Polyphenol-rich Indian ginger cultivars ameliorate GLUT4 activity in C2C12 cells, inhibit diabetes-related enzymes and LPS-induced inflammation: an in vitro study. J Food Biochem 45(2):66

160. Bonetti N, Liberale L, Akhmedov A, Pasterk L, Gobbato S, Puspitasari $Y$ et al (2021) Long-term dietary supplementation with plant-derived omega-3 fatty acid improves outcome in experimental ischemic stroke. Atherosclerosis 325:89-98

161. Serrano G, Kochergina I, Albors A, Diaz E, Oroval M, Hueso G et al (2020) Liposomal lactoferrin as potential preventative and cure for COVID-19. Int J Res Health Sci 8(1):08-15

162. Mu C, Sheng Y, Wang Q, Amin A, Li X, Xie Y (2021) Potential compound from herbal food of Rhizoma Polygonati for treatment of COVID-19 analyzed by network pharmacology: viral and cancer signaling mechanisms. J Funct Foods 77:104-149

163. Mustafa M, Shamsuddin S, Sulaiman S, Abdullah J (2020) Anti-inflammatory properties of stingless bee honey may reduce the severity of pulmonary manifestations in COVID-19 infections. Malay J Med Sci 27(2):165-169

164. So A, Woo J (2020) Reserving coronavirus disease 2019 vaccines for global access: cross sectional analysis. BMJ 66:m4750

165. Coronavirus: WHO chief criticises 'shocking' global vaccine divide [Internet]. BBC News. 2021 [cited 12 June 2021]. https://www.bbc.com/ news/world-56698854

166. Higgins-Dunn N. Pfizer, AstraZeneca COVID vaccines probed in Europe after reports of heart inflammation, rare nerve disorder [Internet]. FiercePharma. 2021 [cited 13 June 2021]. https://www.fiercepharma. com/pharma/europe-s-drug-regulator-evaluates-reports-heart-infla mmation-rare-nerve-disorder-covid-19

167. Vangeel L, Chiu W, De Jonghe S, Maes P, Slechten B, Raymenants J et al (2022) Remdesivir, Molnupiravir and Nirmatrelvir remain active against SARS-CoV-2 Omicron and other variants of concern. Antiviral Res 198:105252. https://doi.org/10.1016/j.antiviral.2022.105252

168. Jayk Bernal A, Gomes da Silva M, Musungaie D, Kovalchuk E, Gonzalez A, Delos Reyes V et al (2022) Molnupiravir for oral treatment of Covid-19 in nonhospitalized patients. N Engl J Med 386(6):509-520. https://doi. org/10.1056/nejmoa2116044

\section{Publisher's Note}

Springer Nature remains neutral with regard to jurisdictional claims in published maps and institutional affiliations. 